\title{
Recursos narrativos en la comedia muda de Hollywood
}

\section{Narrative Resources in Hollywood's Silent Comedy}

\section{Jaume Radigales}

Universitat Ramon Llull (España)

La comedia muda del primer cine de Hollywood se basa en unos recursos expresivos y narrativos que demuestran la voluntad no explícita de experimentación del género, así como la intención de divertir al público. Consciente o inconscientemente, los primeros realizadores y actores de aquellas películas asumieron las convenciones del teatro, de la pantomima y de cierta literatura para ofrecer unos trabajos muy libres en el fondo y en la forma, y que tendrían gran transcendencia en el futuro, como el mecanismo del gag o los trucos visuales. Este texto expone las principales características y tratamiento de tales recursos (automatismo, quid pro quo, violencia y transgresiones, erotismo y travestismo) a través de personajes clave de aquel periodo: Mack Sennett, Charles Chaplin, Buster Keaton o Roscoe Arbuckle, entre otros.

Palabras clave: comedia, Estados Unidos, slapstick, cine mudo, narrativa cinematográfica.
Silent comedy in Hollywood's early cinema is based on expressive and narrative resources that show the non-explicit desire for experimentation in the genre, as well the intention to amuse the audience. Consciously or unconsciously, the first directors and actors of those movies assumed the conventions of theatre, pantomime and some literature to offer works which were very free in both form and content, and which would be highly influential in the future. This article shows the principal characteristics and the treatment of these resources (automatism, quid pro quo, violence and transgressions, eroticism and transvestism) through key personalities of that period: Mack Sennett, Charles Chaplin, Buster Keaton and Roscoe Arbuckle among others.

Keywords: comedy, United States, slapstick, silent movies, narration in film. 

l psiquiatra y ensayista Carl Gustav Jung se refirió al hombre como productor de símbolos que perviven bajo formas estructurales atemporales (los arquetipos). Aceptando esta idea, estaremos de acuerdo con el carácter a veces inconsciente de las formas de representación, incluido el cine.

Tal principio puede aplicarse a la comedia del primer cine hollywoodiense, cuyos artífices crearon y recrearon situaciones y estructuras narrativas a partir de unos recursos que a menudo escapan a las convenciones de lo previsible, para adentrarse en el terreno de lo creativo y lo insólito.

En las comedias de Mack Sennett, el creador de esas comedias fundacionales, hay una especie de pulsión inconsciente hacia la asunción de determinados esquemas fijos que se enmarcan en los caracteres, en los arquetipos literarios y teatrales, sin otro objetivo que el de hacer reír al espectador; caracteres que viven de recursos que se mantienen incólumes en los personajes de la gran pantalla. Algunos de esos recursos, que aparecen constantemente en la mirada de realizadores y en los gestos de los actores, son los que se verán a continuación. Todos ellos, en todo caso, no pretendían mostrar "la representación de la vida [...] sino la caricatura de la vida" (Turconi, 1966: 27). Veamos cómo.

\section{EL GAG Y EL AUTOMATISMO DEL CUERPO HUMANO}

En la comedia norteamericana muda, el gag actuó a modo de contrapunto narrativo. El cuerpo humano como objeto primario de la risa, el estilo cómico de los actores y actrices (con una personalidad propia, pero que también tomaba prestados elementos de compañeros y rivales en pantalla), el automatismo y las confusiones diversas dieron pie a un lenguaje artístico que, aun basándose en algo tan antiguo como la pantomima, se adentró en los recovecos de un arte nuevo, emergente del reino de las sombras.

El término gag es ambiguo. Sin meternos en el terreno de la etimología, en el slapstick el concepto designará lo que según Gianni Celati es una manifestación absolutamente liberada de la lógica dramática: "Un mecanismo secundario, de relleno, se convierte en el mecanismo principal, removiendo las bases mismas de la lógica dramática" (Cremonini, 1978: 18).

Ahora bien, otorgar al gag la única finalidad de estas películas es negar a aquellos productos una narratividad derivada del teatro y sus distintos subgéneros, como las variedades, el vaudeville, el music-hall o el burlesque (King, 2002: 24). Claro que muchas comedias slapstick están basadas íntegramente en engranajes cosidos a base de gags, pero son estos, precisamente, los que dieron al cine una nueva textualidad: la cómica. Como apunta Giorgio Cremonini, estas películas se convirtieron, gracias al gag, en estilizaciones del referente narrativo a las que deben su originalidad: "El gag desestructura una situación dada (a su vez estructurada con base en la lógica dramática) para reestructurarla según criterios diversos" (Cremonini, 1978: 20). Criterios que pueden originarse en la propia creación de máscaras, de automatismos, en reiteraciones y variaciones, etc.

Decía Henri Bergson que "las actitudes, gestos y movimientos del cuerpo humano son risibles en la exacta medida en que ese cuerpo nos hace pensar en un 
mismo mecanismo" (Bergson, 1999: 22-23). Exacto: el cuerpo humano es risible en cuanto mecanismo y, cuando esto falla, lo risible se encarna en un signo externo, de corte fisiológico y netamente subjetivo (aunque no por ello menos contagioso), que es la carcajada. Este automatismo, que en teatro funciona a partir de una exageración gestual notoria, ha de ser calculado y medido en la pantalla, porque puede comprometer el exceso (al estilo del actor Ford Sterling) pero puede enfatizar lo sutil (Buster Keaton). Todo ello sin dejar de recurrir al automatismo, como la escena del almacenaje de Naranjas y limones (Oranges and Lemons, ${ }^{1}$ George Jeske, 1923), protagonizada por Stan Laurel. ${ }^{2}$

El gag requiere un elemento poético en el contexto naturalista proporcionado por la pantalla y, de acuerdo con Cremonini, ha de basarse en el uso de la caricatura (la máscara), en la construcción narrativa del propio gag y en el ritmo (Cremonini, 1978: 50); aunque cabría añadir a todo ello la relación de la persona con los objetos, por ejemplo, en algunas de las comedias de Chaplin o de Keaton.

Por todo ello, la mecanización del gag en forma de repetición será un recurso cómico, aunque solamente cuando en algunas de las reiteraciones exista un elemento de variación, que coge por sorpresa al desprevenido espectador: en Perro con suerte (Lucky Dog, Jess Robbins, 1919), el personaje interpretado por Stan Laurel está a punto de ser atropellado en dos ocasiones por un tranvía cuando el actor se encuentra en medio de la calle. A la tercera, lo atropella un coche. Algo parecido ocurre en El terror de los bosques (Boobs in the Wood, Harry Edwards, Mack Sennett, 1925), en la que Harry Langdon intenta cortar un árbol. En el primer impacto, el rebote hace que Chester (Langdon) salte por los aires. Lo mismo en el segundo. En el tercer intento, será el hacha la que salte por los aires y rebote contra varios árboles y otros leñadores. En la misma película, Chester bebe un vaso de aguardiente que le provoca una caída fulminante. En la segunda ocasión prefiere beber del vaso, pero antes se sienta en el suelo para no volver caer. El gag funciona, aquí, sobre lo que podría denominarse automatismo con variaciones.

En las películas de Charles Chaplin, maestro de las variaciones, la repetición del gag obedece a la equivalencia del efecto cómico producido en teatro por la repetición de una palabra, recurso habitual en los "cannovacci" de la Commedia dell'arte o en sus herederos, como las comedias de Molière y Goldoni. ${ }^{3}$ Porque,

1 A lo largo del artículo, se citan diversos títulos de películas. Se incluye la traducción del título de todas ellas: entre paréntesis, los títulos traducidos de aquellos filmes estrenados en España, y entre corchetes, los inéditos, y cuya traducción es del autor del artículo.

2 A pesar de todo, Bergson se refiere también al recurso cómico entendido desde la asepsia, desde la insensibilidad del espectador (Bergson, 1999: 111), argumento con el que no podemos estar del todo de acuerdo, porque, efectivamente, el efecto de una determinada secuencia (en este caso cinematográfica) puede ser cómico, independientemente de la implicación emocional y sensitiva del espectador.

3 La referencia a la Commedia dell'arte - forma popular italiana cuyos orígenes se remontan al siglo XV y cuyos personajes actuaban bajo máscaras físicas y caracterológicas - no es baladí: Kathleen Chamberlain es una de las autoras que mejor ha estudiado la equivalencia entre 
como dice Bergson en relación a Tartufo, "en una repetición cómica de palabras están presentes generalmente dos temas, un sentimiento comprimido que se detiene como un resorte y una idea que se divierte comprimiendo nuevamente el sentimiento" (Bergson, 1999: 56). Sustitúyase "palabras" por "gestos" y veremos que la equivalencia funciona. El pensador francés enfrentaba la inteligencia a la sensibilidad, siempre desde el plano de lo cómico como exclusivamente humano. En este sentido, la comedia cinematográfica busca lo sensible en el recurso de lo cómico, al mismo tiempo que encuentra lo inteligible en la broma, el gag, casi siempre como fruto de su mecanismo-automatismo. A menudo, tal automatismo se produce como reacción en cadena; de ahí la efectividad de las escenas de la factoría Sennett con las que concluyen muchos de los slapstick de la Keystone.

A veces, el automatismo con variación basa esta última más que en la lógica de lo previsible, en la inversión cuando un gag no se resuelve con base a lo previsto, sino a lo imprevisto. De hecho, este es ya el modelo seguido por los hermanos Lumière en El regador regado (L'arroseur arrosé, Louis Lumière, 1895), del que Chaplin tomó buena nota, a pesar de la distancia temporal entre el film de los Lumière y las primeras grandes comedias de Chaplin (a partir del periodo con la Essanay, en 1915), veinte años después de la película francesa y con un sistema de producción muy elaborado e incluso sofisticado y, en el caso de Chaplin, sustentado en el perfeccionismo obsesivo del cineasta británico.

La repetición y reiteración del gag, en todo caso, deben su eficacia a situaciones posteriores al mismo: por ejemplo el número de "víctimas" que provoca, una persecución o un clima creciente de violencia, contenedora asimismo de otros gags derivados del primero (King, 2002: 23).

Por otra parte, el recurso de la inversión antes citado también puede derivarse de las confrontaciones entre protagonista y antagonista, ya apuntadas por Cremonini, para quien el gag se convierte así en "resolución de un contraste dado entre un protagonista y un Otro" (Cremonini, 1978: 25).

El automatismo es difícil de resolver si no se planifica de modo coreográfico. Es en las comedias de Chaplin donde mejor se ve una planificación como si de un ballet se trataran, porque lo coreográfico es un fin en sí mismo. En el cine de Chaplin "el ballet crea un Tiempo y un Espacio que le son propios. Un tiempo musical, inserido en el gesto, y que lo lleva a su medida. El gesto de Charlot [...] imprime un ritmo particular al tiempo del mundo y de las cosas que, desde entonces, se pliega a la duración que se le da. De tal modo que Charlot domina o parece dominar lo real actuando sobre el 'tiempo del gesto'" (Mitry, 1957: 72). Pero lo coreográfico no es únicamente chapliniano: ¿cómo, si no, se hubiera planteado la escena en la que Buster Keaton sigue con obstinada tozudez a quien sospecha que es el ladrón en Sherlock Jr. El moderno Sherlock Holmes (Sherlock Jr., Buster Keaton, 1924)? La coreografía, en definitiva, confiere al gag su pleno sentido ontológico.

los arquetipos del teatro italiano y los personajes cómicos de la comedia norteamericana muda (Rickman, 2001: 53-59). 


\section{EL ‘QUID PRO QUO’ COMO CONVENCIÓN NARRATIVA}

El poeta Jean Paul Richter sostenía que la comicidad radica en el sujeto (Berger, 1997: 62-69), cosa que puede explicar otro de los recursos más atractivos para un profesional del humor: la inversión del carácter (o del rol) de un determinado sujeto, el quid pro quo.

En muchas ocasiones, estos recursos abren la puerta a la sátira social, por ejemplo, cuando Chaplin se hace pasar por aristócrata en El conde (The Count, Charles Chaplin, 1916) o cuando él mismo asume las tareas de un dentista siendo en realidad el chico de la limpieza en Charlot, falso dentista (The Laughing Gas, Charles Chaplin, 1914). La gracia del asunto, al menos en esta última película, estriba en el hecho de que el espectador es víctima del engaño, de la inversión, porque el "sujeto" no muestra su verdadera profesión hasta que recoge las escupideras de la consulta, momento que aprovecha el actor británico para cambiar de pose y reducir la prepotencia con la que se acaba de presentar ante los pacientes, antes de asumir una actitud mucho más retraída. Y, de hecho, ¿no es un inmenso quid pro quo el punto de partida de Luces de la ciudad (City Lights, Charles Chaplin, 1931), donde una vendedora ambulante de flores ciega toma a un vagabundo por un millonario? A partir de ahí, el personaje interpretado por Chaplin tendrá que esforzarse por ser lo que no es, pero a quien la chica toma por real: un mecenas despreocupado por su fortuna y dispuesto a ayudarla. La resolución del quid pro $q u o$ adquiere en este sentido plena significación en el admirable plano final de la película, después del breve diálogo mostrado en los intertítulos. ${ }^{4}$ La imagen se fundirá a negro, con lo que el realizador nos deja en vilo: el quid pro quo se ha resuelto, pero no conocemos sus consecuencias. ${ }^{5}$

El quid pro quo, que también asume sus consecuencias con el travestismo (que veremos más adelante), tiene que ver con el sujeto y su entorno material-objetual: en El hombre mosca (Safety Last, Fred Newmeyer, Sam Taylor, 1923), protagonizada por Harold Lloyd, la verja que separa a los dos enamorados parece en un primer momento como los barrotes de un calabozo, mientras que a lo lejos hay algo que parece una horca. La despedida ante el cura acrecienta el dramatismo de la situación, que finalmente se muestra con toda su veracidad: el personaje que interpreta Harold Lloyd no es más que un chico de provincias que se despide de su novia para ir a la ciudad donde, presumiblemente, triunfará. ${ }^{6}$

4 -VAGABUNDO: ¿Puedes verme ahora? -CHICA: Sí, ahora puedo verte.

5 En el caso de esta película, hay que tener en cuenta que se produjo y filmó en plena eclosión del sistema sonoro, pese a lo cual Chaplin quiso mantenerse fiel al gesto y a la pantomima, desafiando un sistema de producción que aceleró el proceso hacia la hegemonía de los talkies o películas habladas y arrinconando un cine, mudo, que pronto fue olvidado.

6 El recurso de los barrotes es algo que Buster Keaton ya había utilizado al principio de El chivo (The Goat), codirigida en 1921 con Malcolm St. Clair. En la secuencia inicial, Keaton se asoma a un calabozo y es retratado como si fuera un convicto. De ahí arranca el corto, verdadera obra maestra del quid pro quo. 
Sin embargo, el quid pro quo puede actuar también como punto de partida, tal es el caso de El chivo (The Goat, Buster Keaton, Malcolm St. Clair, 1921), en que Keaton es víctima de las casualidades al ser confundido por un convicto fotografiado por azar ante los barrotes de una cárcel, lo que desencadena el drama interno del personaje y, externamente, el nudo de la comedia.

A veces, es el desenlace el que actúa como quid pro quo; por ejemplo ante secuencias oníricas en las que el espectador asume el "engaño" al final, tal como ocurre en Charlot portero de banco (The Bank, Charles Chaplin, 1915), en la que el vagabundo sueña que es un héroe capaz de reducir a los atracadores del banco donde trabaja, cosa que resulta ser un sueño. En ¡Buenas noches enfermera! (Good Night, Nurse!, Roscoe Arbuckle, 1918), Fatty, víctima del éter, sueña que es confundido por un corredor de fondo que incluso lleva el número dorsal en la camiseta al haberse apoyado en un árbol con un cinco pintado en el tronco.

\section{TRANSGRESIONES E IRREVERENCIAS}

Existe en la comedia una dimensión dionisiaca, gracias a la transgresión (y a la violación) de los límites (Berger, 1997: 52-53). Por ello, es fácil constatar que otro de los aspectos característicos de este tipo de películas sea la reiterada burla hacia la autoridad. También es algo heredado de la tradición literaria, que acude a la risa "político-social" (D’Angeli, Paduano, 2001: 71-125) y que tiene sus orígenes en las comedias aristofánicas.

Sennett era amante de situaciones en las que, sobre todo los policías, quedaban ridiculizados, pero la broma no tenía más transcendencia, a pesar de que Bergson hubiera dicho que la risa actúa como correctivo social. Claro que una cosa es meterse con la policía y otra muy distinta con estamentos mucho más "intocables". En ese sentido, había que ser muy cauto, muy listo o sentirse (y ser) muy libre para meterse, por ejemplo, con la religión o para utilizar una lacra social como la drogadicción como punto de partida para lo cómico. Pues bien, una película como Charlot en la calle de la paz (Easy Street, Charles Chaplin, 1917) es un compendio de lo que Chaplin haría más adelante en la escena de la cárcel en Tiempos modernos (Modern Times, Charles Chaplin, 1936), que incluye la visita del pastor (y señora). La droga y la Iglesia anglicana son algunos de los blancos hacia los que apunta Chaplin en ambos títulos. Claro que también en El aventurero (The Adventurer, Charles Chaplin, 1917) y en Charlot en el balneario (The Cure, Charles Chaplin, 1917) hay sendas burlas hacia la autoridad policiaca y médica respectivamente, por no hablar del cruel retrato de la sociedad que frecuentaba los balnearios en la última de las películas citadas. Pero Charlot en la calle de la paz es un extraordinario trabajo de síntesis donde lo burlesco toma distancia ante lo serio: el indigente clavándose la jeringuilla antes de intentar violar al personaje que interpreta Edna Purviance relega la sátira del templo a un segundo plano. Desde la burla a la autoridad (en este caso eclesial), Chaplin erige su crítica social. Algo de ello se reencontrará en El peregrino (The Pilgrim, Charles Chaplin, 1923), aunque el anticlericalismo se vea más reducido y constreñido a un plano (no por ello menos admirable) cómico. 
La burla hacia la autoridad confiere una cierta superioridad, ya atisbada por Freud, hacia el objeto de la risa. Esa superioridad es de corte infantil y tiene que ver con la reiteración antes apuntada. Un niño, según el médico vienés, se da cuenta de lo que es gracioso y cae en la reiteración: "Sea cualquiera el motivo a que obedeció el niño al comenzar estos juegos, más adelante prosigue, dándose perfecta cuenta de que son desatinados y hallando el placer en el atractivo de infringir las prohibiciones de la razón" (Freud, 1996: 111). Y no hay nada más tentador que saltarse las leyes y a quienes las ostentan.

Claro que a veces este desafío a la autoridad es inconsciente, y eso es lo que le pasa a Buster Keaton en La mudanza (Cops, Buster Keaton, Eddie Cline, 1922), cuyo título original remite a lo que será punto neurálgico del cortometraje: la persecución de Keaton por parte de cientos de policías, convertidos en una "máquina gigantesca" (Knopf, 1999: 65). Esta hiperbólica escena es mucho más sutil que lanzar directamente tartas de nata al rostro del policía, porque convierte al perseguido en víctima y verdugo a la vez.

\section{UN CINE VIOLENTO}

La transgresión, la burla y la sátira implican muchas veces una innegable violencia que atraviesa de principio a fin este tipo de películas. Las persecuciones, las caídas, las tartas de crema lanzadas directamente a la cara, las bofetadas y patadas, etc., todo ello forma parte de un mundo y de unos personajes. También los lazzi de la Commedia dell'arte consistían en realizar actos violentos y muchos de los temas de las películas slapstick serán tratados de la misma forma en las futuras series de dibujos animados de la Warner Brothers o de la Metro Goldwyn Mayer, con sus características excentricidades y transgresiones visuales. Y la violencia formará parte, igualmente, de los cartoons de dichas productoras. Charlot bombero (The Fireman, Charles Chaplin, 1916) es seguramente una de las películas que mejor ejemplifica esta violencia, sobre todo en sus secuencias iniciales: el jefe de bomberos propina una monumental paliza a Chaplin, un sufrido bombero que será, sin quererlo, el héroe de la historia. El jefe patea el trasero de su subordinado y al principio se busca la comicidad a través de esta violencia. Pero, pronto, la reiteración sistemática y expresamente planteada por Chaplin da a la situación un innegable patetismo: la violencia explicitada distancia y crea en el espectador un criticismo a partir, precisamente, de tal distanciamiento, de corte netamente brechtiano. El mismo, por ejemplo, que podemos aplicar a la magistral batalla campal de La batalla del siglo (The Battle of the Century, Clyde Bruckman, Hal Roach, 1927), que después del resbalón de un pastelero muestra lanzamientos diversos de tartas de crema entre Stan Laurel y Oliver Hardy, pero que, sin querer (aunque sea previsible), van a parar a la cara de algunos transeúntes que se enfrascan en la ya citada batalla campal.

Esa violencia tiene que ver con el proceso de tensión-distensión que se espera en películas de este calibre. En 1930, Buster Keaton escribió: "La mejor manera de provocar risa es crear un momento angustioso y aliviar después la tensión solucionando el asunto cómicamente. La risa está condicionada por el elemento 
inesperado, y lo inesperado es cada vez más difícil, porque el público, acostumbrado a los asuntos cinematográficos, se sabe ya casi todas las respuestas. Pero si se inventa una situación escalofriante, se da forma y se la soluciona después de un modo ridículo, el elemento de sorpresa queda asegurado" (Montgomery, 1955: 180). Buen ejemplo de ello es Una semana (One Week, Buster Keaton, Eddie Cline, 1920), en la que Keaton queda en medio de una vía de tren. Sin que él se dé cuenta, el convoy se acerca irremisiblemente haciendo temer lo peor. A pocos metros del protagonista, y de golpe, el convoy se desvía porque hay una vía secundaria, que es la que toma el tren.

\section{TÉCNICAS, TRUCOS Y MONTAJES}

Técnicamente, las comedias que comentamos se resuelven con soluciones felices y que coinciden con las propuestas gramaticales y sintácticas del creador de la narrativa cinematográfica por excelencia, David W. Griffith. No es de extrañar, por ello, que Keaton le rindiera su particular homenaje paródico en Las tres edades (The Three Ages, Buster Keaton, Eddie Cline, 1923) amparándose en la mastodóntica Intolerancia (Intolerance, David W. Griffith, 1916). En este sentido, el montaje paralelo que el director norteamericano haría célebre en la controvertida El nacimiento de una nación (The Birth of a Nation, 1915) ya estaba presente en algunos slapstick de la factoría Sennett, como en Todo por un paraguas (Between Showers, Henry Lehrman, 1914), con dos protagonistas antagonistas en los roles principales: Ford Sterling y un todavía debutante Charles Chaplin. La película muestra la denuncia de Sterling a la policía por haber sido agredido por Chaplin, mientras este flirtea con una muchacha con el único objetivo de robarle un paraguas.

Más adelante, el mismo Chaplin utiliza el montaje paralelo, por ejemplo en Charlot perfecta dama (A Woman, Charles Chaplin, 1915), o incluso, de manera más sofisticada, en Los ociosos (The Iddle Class, Charles Chaplin, 1921), para narrar las complejas situaciones de los personajes, en el contexto de uno de sus cortos más elaborados.

El montaje analéptico, a modo de flashback, o las elipsis temporales también aparecen en algunas comedias. Un ejemplo magistral es uno de los mejores cortos de Keaton, El herrero (The Blacksmith, Buster Keaton, Malcolm St. Clair, 1922), en el que la última secuencia es una elipsis que muestra al personaje de Keaton felizmente casado con la chica (Virginia Fox) que años atrás había sido víctima de su inoperancia como herrero.

La narratividad visual, pues, y un sentido de la gramática y sintaxis cinematográficas eran preocupaciones de aquellos realizadores, que iban mucho más allá de la filmación de acciones espontáneas y más o menos improvisadas: si se improvisaba, se hacía sobre guiones previamente establecidos, como lo demuestran las tonterías de Langdon en Sus primeros pantalones (Long Pants, Frank Capra, 1927) ante una cámara que recurre a un plano cenital, recurso aún raro en aquel momento. Todo ello unido a trucos de todo tipo, como la trayectoria extraña del balón en Dedos de mantequilla (Butter Fingers, Lord, 1925) o los gags basados en "efectos especiales" de Hoy circo (Circus Today, Lord, 1926) y Vagones de agua (Water Wagons, Lord, 1925). Por no hablar de riesgos de todo tipo: en Charlot 
prestamista (The Pawnshop, Charles Chaplin, 1916), Chaplin limpia unos cristales desde lo alto de una escalera que se balancea hasta caer: él se levanta y sólo se preocupa por comprobar si el reloj aún funciona; en El heróe del río (Stemboat, Bill, Jr., Charles F. Reisner, 1928) a Keaton le cae encima la fachada de una casa y se salva porque el ventanuco pasa a través de su cuerpo; en Yukon Jake (Lord, 1924), y mucho antes de que Chaplin patinara con los ojos vendados en un altillo sin protección (en Tiempos modernos), un cowboy duerme en su mecedora al borde de un profundo hueco. El riesgo existía, pero aquellos hombres y aquellas mujeres sabían lo que se hacían. Y es que puede que el cine estuviera en su fase primitiva, pero la originalidad de algunas de sus propuestas da pie a pensar que aquellos pioneros jugaban experimentalmente a socavar las bases de la comedia.

\section{EROTISMO, FEMINEIDAD Y TRAVESTISMO}

En la comedia norteamericana de las dos primeras décadas del siglo XX existen diversos estereotipos, que se dividen en sexuales, raciales y de situación. Los primeros tienen que ver con la figura femenina y su tratamiento. Heroínas de la pantalla como Edna Purviance, Mabel Normand, Mildred Davis, Bebe Daniels, Louise Fazenda, Alice Howell o Gale Henry personifican tipos diversos. A ellas hay que unir la presencia de astros de los escenarios como Marie Dressler, cuyo cameo en El romance de Charlot (Tillie's Punctured Romance, Mack Sennett, 1914) le abrió las puertas a la fama internacional. Pero también cabe contar con la presencia de algunas de las Bathing Beauties de Mack Sennett como Carole Lombard o Gloria Swanson, que de comparsas pizpiretas pasaron a ser grandes estrellas del cine mudo y de los primeros talkies. Chicas bañistas que, no obstante, mantuvieron también su presencia en películas en las cuales no aparecían con su atuendo playero, pero que cumplían la misma función como fetiche erótico: el mismo Chaplin las incluyó como comparsas sensuales en su Charlot prehistórico (His Prehistoric Past, Charles Chaplin, 1914).

Las intenciones de las comedias norteamericanas de las primeras décadas del siglo XX estaban completamente alejadas de los modelos vampirescos de actrices como Pola Negri, Theda Bara, Greta Garbo, la futura Gloria Swanson o Heddy Lamarr. A pesar de todo, hay notas de corte erótico que, bajo los parámetros de lo cómico, dejaban escapar no poca picaresca con base a modelos femeninos. Dejando a un lado las Bathing Beauties, encontramos la presencia de actrices que se presentaban con poca ropa y en secuencias que, a pesar de provocar hoy hilaridad e incluso cierta vergüenza ajena, como el baile de ninfas de la chapliniana Al sol (Sunnyside, Charles Chaplin, 1919), tuvieron en su día una irresistible eroticidad. Pero no todo termina con la semidesnudez, ya que el elemento erótico también se encarna en personajes y profesiones que siempre hemos asociado a situaciones eróticas.

Los desnudos no aparecen en las comedias, destinadas a todos los públicos, pero en algunos casos el cuerpo femenino actúa como excusa para solucionar algunas escenas. Tal es el caso, por ejemplo, del desnudo en la bañera de Sybil Seely en Una semana: la chica está en la bañera y le cae la pastilla de jabón, mira 
34 a la cámara y pide un poco de discreción, tras lo cual la mano del operador de cámara tapa por unos momentos el objetivo para destaparlo al poco rato y, seguidamente, la actriz parece dar las gracias al cameraman. ${ }^{7}$

Todo ello responde a aspectos de un cierto erotismo que provienen de recursos extraídos del teatro de vaudeville, en el que aparece lo que Robert Knopf denominó "excitación de lo burlesco" (Knopf, 1999: 45) y que bien puede ejemplificarse con Una semana, que vincula lo erótico a un cierto voyerismo que se explicita con la intervención (imprevista e inesperada) del operador de cámara.

Precisamente, el voyerismo se pone a menudo al servicio de una eroticidad mucho más perversa, especialmente en erotómanos consumados como Roscoe Arbuckle. En La sencilla vida de Fatty y Mabel (Fatty and Mabel's Simple Life, Roscoe Arbuckle, 1915), Fatty y Mabel Normand trabajan en su granja, y la muchacha cuida su ternero. Llevan una vida sencilla y se quieren. En una escena de la película, Fatty espía a través de un agujero a Mabel, que está ordeñando una vaca. Desde su puesto de vigilancia, Fatty beberá la leche que entra a chorro por un agujero hacia el cual Mabel dirige el líquido de las ubres de la vaca. No se podía ser más explícito.

En los cannovacci de la Commedia dell'arte, los personajes femeninos estaban ligados a estereotipos como los de enamoradas, sirvientas o cortesanas (Uribe, 1983: 66-68). Estos son también los papeles que las mujeres interpretan en las películas slapstick, aunque la personalidad de algunos de los realizadores imprimiera a la mujer un rol autónomo, a pesar del peso específico de un protagonista al estilo de Chaplin, Keaton o Lloyd. Buster Keaton, por ejemplo, mantiene con la mujer una relación mucho más normal que en las películas de Chaplin: la chica es, por encima de todo, razón de ser de las peripecias keatonianas. Un personaje fundamental, al revés de Chaplin, quien utiliza a la mujer como soporte para el encumbramiento del vagabundo asumido por el realizador británico.

También se encuentran en estas películas modelos femeninos estereotipados bajo el prisma de la mujer horrible, asexuada y caricaturescamente perversa, como la esposa de Chaplin en Día de paga (A Pay Day, Charles Chaplin, 1922) o la espectadora fea de Charlot en el teatro (A Night in the Show, Charles Chaplin, 1915); por no hablar de los tópicos sexistas (perfectamente asumibles en el contexto de su tiempo pero hoy políticamente incorrectos) que aparecen en relación a las mujeres y a sus dedicaciones cotidianas, como en El castillo encantado (Haunted Spooks, Hal Roach, Alf Goulding, 1920), en que Mildred Davis se casa con Harold Lloyd y cuando se encuentra ante el sacerdote, le dicen: "Aquí tiene usted un marido, un sacerdote, un anillo y un libro de cocina". Sobran los comentarios.

En el contexto de las primeras comedias norteamericanas no parece haber el equivalente de una mujer-actriz-estrella. La suerte efímera de Mabel Normand se concentró en unos pocos años de su carrera, a pesar de una abundante filmografía, gracias a la perspicacia y el buen ojo de Mack Sennett. Pero dejando a un lado a Normand, actrices como Edna Purviance, Natalia Talmadge, Virginia Fox, Sybil

7 Un claro ejemplo de ocularización interna primaria y subjetiva, de acuerdo con los postulados de François Jost. 
Seely, Minta Durfee o Mildred Davis no dejaron de ser acompañantes o comparsas oficiales de las verdaderas estrellas tales como Chaplin, Lloyd, Larry Semon o Arbuckle, con la excepción de Keaton, quien, como se ha visto, da a la mujer una importancia relevante por su papel activo y decisivo en el desarrollo de la trama.

Por su parte, la actriz Gale Henry aprovechó su fealdad y su estrabismo (un equivalente femenino de Ben Turpin) para fundar su propia compañía — como hiciera Mabel Normand-, con la que cosechó éxitos que no pasaron de ser efímeros, como el notable corto La detective (The Detectress, 1919), seguramente dirigido por ella misma. Menos suerte tuvo Alice Howell, otra gran comedianta de su tiempo, que en Una noche húmeda (One Wet Night, William H. Watson, 1924) interpreta a una mujer burguesa en una película con la lluvia como telón de fondo de las situaciones previsiblemente cómicas. Por su parte, Fay Tincher interpretó casi siempre el papel de Ethel en comedias de Al Christie como Rowdy Ann (1919), en la que excepcionalmente asume el rol de Ann, una chica del lejano oeste que ayuda a su padre en las tareas ganaderas y que es enviada a la ciudad. Allí, tendrá que actuar como bailarina, pero sus aires rústicos y campestres chocan con el refinamiento que se atribuye a una chica de comportamiento políticamente (o sexualmente) correcto.

Para Mack Sennett, las mujeres tenían un sentido del humor innato, sobre todo si se las dirigía sin demasiadas instrucciones (Turconi, 1966: 116-117). Por ello, el realizador canadiense contó entre sus estrellas a cómicas de gran intuición, como su musa Mabel Normand, Louise Fazenda o Marie Dressler, la célebre actriz teatral francesa.

Por su parte, Mabel Normand fue una auténtica estrella, sobre todo en las películas que interpretó junto a Roscoe Arbuckle, ya que su encuentro con Chaplin se saldó con diversos chispazos que terminaron por dinamitar una relación de competencia y de lucha por el poder que se resolvió con el triunfo absoluto del cómico británico. La verdad es que entre Normand y Chaplin hubo sin duda una rivalidad que Mack Sennett tuvo que tolerar, habida cuenta del olfato del productor canadiense para las estrellas. Y Chaplin estaba destinado a ser una estrella, mientras que Normand estaba condenada a brillar como astro en el firmamento de su época, sin que sus películas tuvieran más trascendencia. Claro que Sennett tampoco se planteaba realizar productos que tuvieran vida más allá de su tiempo, y su relación amorosa con la citada actriz hizo que la defendiera a pesar de reconocerle una calidad artística que estaba a años luz de la chapliniana.

En sus películas, Normand acostumbra a interpretar el papel de una chica atractiva, con no pocas dosis de picardía y siempre dispuesta a salirse con la suya o a rebelarse contra comportamientos machistas: en La carrera dramática de Mabel (Mabel's Dramatic Career, Mack Sennett, 1913), el personaje interpretado por el mismo Sennett golpea el trasero de Mabel y ella le lanza la vajilla a la cabeza. En El día de limpieza de Mabel y Fatty (Mabel and Fatty's Wash Day, Roscoe Arbuckle, 1915), es una mujer trabajadora, casada con un holgazán. Por contra, su vecino (Arbuckle) está explotado por su esposa, que le obliga a realizar las más variadas y arduas tareas domésticas. Mabel y Fatty tienden la ropa y se confunden de colada. De ahí emerge una relación en la que ambos se quejan de los respectivos cónyuges, hasta despertar los celos de ellos. El segundo episodio del cortometra- 
je transcurre en un parque, en el que coinciden Mabel y Fatty. Sus respectivas parejas se duermen y los dos vecinos pasean por el parque y toman un helado, que Fatty paga con el dinero que sustrae del monedero de su esposa. Al final, las peleas se suceden hasta que Fatty cae sin sentido después de haber recibido un porrazo de un policía.

En cambio, Fatty y Mabel en la exposición de San Diego (Fatty and Mabel at The San Diego Exposition, Roscoe Arbuckle, 1915) muestra a la pareja cómica como un matrimonio en el que Fatty no duda en flirtear con otras muchachas. Harta de sus infidelidades, Mabel se disfraza de bailarina exótica y aparece en el escenario de un local en el que se encuentra Fatty, que, no reconociendo a su pareja, intenta seducirla. Al final, y después de persecuciones al más puro estilo slapstick, se reconcilian. La relación matrimonial que Arbuckle y Normand mantuvieron en pantalla culminó en la Keystone con una de las últimas películas de la citada productora en la que participaron: Fatty y Mabel a la deriva (Fatty and Mabel Adrift, Roscoe Arbuckle, 1916). En este cortometraje, a la pareja citada se les une un tercero en discordia que también tuvo cotas de protagonismo en varias de estas películas: el perro Teddy, testigo de excepción de una relación que se tambalea ante la aparición de un rival de Fatty interpretado por Al St. John, quien al final terminará por dejar en paz al matrimonio gracias a la intervención del can.

La pareja como mundo es lo que aparece en la serie de películas protagonizadas por Normand y Arbuckle, como respuesta al concepto de doble paródico definido por Gianni Celati (Cremonini, 197: 32) y que también podría aplicarse a la única pareja estable que Chaplin se lleva al final de Tiempos modernos: una mujer (Paulette Goddard) como el vagabundo, que vive en cualquier sitio y que parte a la búsqueda de una nueva aventura cuando la pantalla se funde a negro.

El travestismo fue también una de las constantes de este tipo de comedia y como recurso heredado de los orígenes del teatro. El music-hall adoptó aquel modelo, a pesar de que las mujeres ya hacía siglos que aparecían en escena. De hecho, el music-hall "abunda en convencionalismos puestos al revés" (Louvish, 2003: 121).

En el cine, el travestismo se puede leer como la aceptación de una convención más: unas veces como recurso cómico —o grotesco- en sí mismo (cuando el actor interpreta un papel femenino); otras a partir de una simulación o un engaño; y otras como parodia de un modelo ajeno al cine cómico y basado en la ridiculización del estereotipo de la mujer vampiresa, al estilo de Pola Negri o Theda Bara. Esta última aparece citada precisamente en Ahí está otra vez (He's in Again, Chass Parrott, 1919) en la que Billy West, imitando a Chaplin, se trasviste como una vampiresa que se hace llamar "Beda Thara", con una lógica y previsible inversión de las iniciales de la emblemática actriz.

Todo ello teniendo en cuenta que estamos ante un travestismo masculino, porque es poco frecuente el proceso inverso; de todas maneras, cuando las mujeres se visten de hombre lo hacen por cuestiones de necesidad primordial, para escapar de algo o de alguien o para conseguir un propósito para el que han sido rehusadas anteriormente: es el caso de Edna Purviance, que se viste de mozo en Charlot tramoyista de cine (Behind the Screen, Charles Chaplin, 1916) para conse- 
guir trabajo en un estudio cinematográfico; o de Louise Fazenda en Corazones y flores (Hearts and Flowers, Eddie Cline, 1919), que se viste de hombre para poder defenderse de los pesados que la acechan. Mucho más refinadas, las Christie Comedies echaron mano del travestismo con una sutileza mayor y centrada también en el disfraz masculino adoptado por una mujer, como en Conoce a tu mujer (Know thy Wife, Al E. Christie, 1918), en la que Dorothy Devore se viste de hombre, aunque tiene el mal detalle de flirtear con su novio ante la mirada de su futura suegra, que obviamente adivina una relación de corte netamente homosexual.

La necesidad está también detrás de soluciones de travestismo en películas como Botín de amor y accidente (Love, Loot and Crash, Nick Cogley, 1915), en la que Charley Chase y Harold Lloyd se disfrazan de mujer para conseguir trabajo como cocineras en una rica mansión.

Charles Chaplin utilizó —e hizo utilizar - el disfraz femenino en algunas de sus películas, en las que se destacan por encima de todas Charlot perfecta dama y Charlot artista de cine (The Masquerader, Charles Chaplin, 1914). En esta última se interpreta a sí mismo, sin maquillaje, como aspirante a actor (junto a Roscoe Arbuckle) que es rechazado por el director de un estudio cinematográfico. Poco después reaparece como Madame Chaplin y el citado director flirtea con él/ella. Finalmente, aceptado en el estudio, se maquilla con el característico mostacho, pero poco después se descubre el engaño. El desenlace de la película culmina en una persecución al final de la cual Chaplin caerá en un pozo.

Charlot perfecta dama, muy elaborada, nos presenta a un Chaplin que se afeita el bigote para convertirse en una "perfecta" mujer, atractiva y dulce, que será objeto de deseo de dos hombres. La interpretación del actor británico, soberbia, sigue los tópicos de las grandes señoras de la pantalla de aquellos tiempos, aunque sin estereotipos grotescos, que, en cambio, sí utilizó Stan Laurel para travestirse como criada seductora en El detective (The Sleuth, Percy Pembroke, 1925), en la que interpreta a Webster Dingle, un detective que recibe el encargo de vigilar al marido de una rica clienta. Se trata de un playboy en cuya casa Laurel entrará como doncella, a la que obviamente el marido intentará conquistar. Laurel, jugando, le rompe diversos objetos en la cabeza en unas escenas de corte grotesco y con una interpretación bastante tópica, previsible y estereotipada. Sea como sea, tanto en este caso como en el de la última película chapliniana comentada, estamos ante el quid pro quo característico del slapstick, con ribetes de vaudeville plenamente conseguidos y con una resolución de la historia muy inteligente por parte de Chaplin y no tanto de Stan Laurel.

Chaplin utilizó el travestismo para diversas situaciones cómicas (o, mejor dicho, grotescas) encarnadas en intérpretes de su compañía como Henry Bergman, quien aparece como mujer en dos cortos antológicos como Charlot héroe del patín (The Rink, Charles Chaplin, 1916) y Charlot emigrante (The Inmigrant, Charles Chaplin, 1917). En el primero es objeto de deseo de un cliente del restaurante donde trabaja Chaplin, mientras su marido flirtea con la esposa de su rival. Aquí, el travestismo actúa como recurso cómico, lo mismo que sucede en Charlot emigrante, en la que el mismo Bergman (que en la segunda parte de la película interpreta a un visionario pintor) asume el rol de una mujer obesa que rueda por los suelos en la cantina del barco que lleva a los emigrantes a Estados Unidos. Ni 
38 qué decir tiene que la escena es aprovechada por Chaplin para crear un gag en el que él mismo cae al suelo pero encima de la pobre mujer, interpretada por uno de los miembros más fieles y duraderos de la compañía.

Un auténtico especialista del travestismo basado en lo cómico por sí mismo fue Roscoe Arbuckle. Obviamente su obesidad estaba al servicio también de un cierto erotismo perverso, habida cuenta de lo atractivo que resultaba para algunos hombres la generosa carnalidad de las mujeres de aquellos tiempos. En Mirando a escondidas (Peeping Peet, Mack Sennett, 1913) interpreta el papel de la esposa de un hombre (interpretado por el mismo Sennett) que espía a una atractiva rubia con un voyerismo del todo descarado. Más ridículo aún, en Los amantes playeros de Miss Fatty (Miss Fatty's Seaside Lovers, Roscoe Arbuckle, 1916) interpreta a una jovencita, hija de una familia multimillonaria, que llega a un hotel en el que será objeto de burlas y chanzas de todo tipo por parte de unos mozalbetes que cuando intentan flirtear con "ella" reciben espectaculares bofetadas, producidas por la fuerza bruta de Arbuckle. En ocasiones, el travestismo es para Fatty una necesidad para el camuflaje: en Fatty en la feria (Coney Island, Roscoe Arbuckle, 1917) se enfunda en un traje de baño femenino para colarse literalmente en el vestuario de las chicas; mientras que en Fatty asesino (The Butcher Boy, Roscoe Arbuckle, 1917) la excusa para disfrazarse de mujer es el acceso al internado donde reside su novia, Sweet, y cabe decir que su contrincante, Alum (Al St. John), también acudirá al internado, ataviado con un traje femenino. Por no hablar de ¡Buenas noches, enfermera!, en la que Arbuckle se disfraza de monja enfermera para eludir a los médicos que la persiguen.

\section{CONCLUSIONES}

Por la comodidad de un formato breve —el cortometraje- y por su identificación con las clases populares, la comedia devino uno de los géneros más aceptados y consumidos en las dos etapas del cine (el primitivo y el clásico mudo). Con el tiempo, este mismo género se transformó y sofisticó, aunque mantuvo algunas de las constantes de las películas fundacionales, con el empleo de gags y bajo formas como el slapstick, del que tomaron buena nota los cineastas de las generaciones futuras. Y, a pesar de sus orígenes europeos, fue en Estados Unidos donde la comedia implantó unos formatos y unos sistemas de producción propios y genuinos.

A lo largo de poco menos de tres décadas, pues, Hollywood fraguó un modelo de comedia que, a pesar de haber heredado modelos precedentes (sobre todo teatrales y especialmente basados en los arquetipos de la Commedia dell'arte), marcó un camino a seguir para futuras generaciones. Ello fue posible gracias a unos recursos narrativos y expresivos que surgieron de cierta espontaneidad, aunque su carácter osado, transgresor e innovador devinieron elementos experimentales que nutrieron incluso algunas propuestas de vanguardia ajenas al cine comercial: sin ir más lejos, artistas surrealistas como Salvador Dalí y Luis Buñuel, o apóstoles del dadaísmo, loaron las ocurrencias del automatismo keatoniano o el infantilismo de Harry Langdon. 
Consciente o inconscientemente, los padres de la primera comedia cinematográfica en Hollywood asentaron las bases de algo nuevo a partir de la herencia de algo tan viejo como la gestualidad. Y se imponen su estudio y su permanente revisión, para reivindicar un modo eficiente de narrar, así como una ineludible vigencia para entender el estado actual de la comedia visual.

En un contexto como el actual, que permite que desde soportes virtuales se pueda visionar mucho material filmográfico de los primeros treinta años de cine, las nuevas generaciones de espectadores parecen ignorarlo. De no ser así, caerían en la cuenta de que en el terreno de la comedia hace más de ochenta años que ya se había dicho todo.

Jaume Radigales (jaumerb@blanquerna. url.edu) es doctor en Historia del Arte y profesor contratado en la Facultat de Ciències de la Comunicació i Relacions Internacionals Blanquerna de la Universitat Ramon Llull en Barcelona. Imparte las asignaturas de Narración de géneros audiovisuales y de estética y ha sido también profesor de Música y audiovisual y de Cine de vanguardia. Asimismo, estudia las relaciones entre la música y el audiovisual, destacando como investigador principal de los proyectos $\mathrm{I}+\mathrm{D}$ Música y cine en España y El cine musical en España, que dieron pie a distintas publicaciones colectivas.

Es autor de diversos artículos y trabajos sobre la comedia cinematográfica.

Ha publicado, entre otros, los libros Luchino Visconti. Muerte en Venecia, Sobre la música. Reflexions a l'entorn de la música i l'audiovisual, De Plató a Lady Gaga. Estètica i comunicació de masses y El espectáculo operístico.

\section{Bibliografía}

Berger, P. (1997) La rialla que salva. La dimensió còmica de l'experiència humana. Barcelona: Edicions La Campana.

Bergson, H. (1999) Le rire. París: PUF.

Cremonini, G. (1978). Il comico e l'altro. Il comico nel cinema americano. Bolonia: Cappelli editori.

D’Angeli, C. y Paduano, G. (2001). Lo cómico. Madrid: A. Machado Libros.

Freud, S. (1996). El chiste y su relación con lo inconsciente. Madrid: Alianza.

King, G. (2002). Film Comedy. Londres; Nueva York: Wallflower.

Knopf, R. (1999). The Theater and Cinema of Buster Keaton. Princeton University Press.
Louvish, S. (2003). Stan \& Ollie. Las raíces de la comedia. La doble vida de Laurel y Hardy. Madrid: T \& B Editores.

Mitry, J. (1957). Charlot et la "fabulation" chaplinesque. París: Éditions Universitaires.

Montgomery, J. (1955) La comedia en el cine. Barcelona: AHR.

Rickman, G. (ed.) (2001) The Film Comedy Reader. Nueva York: Limelight Editions.

Turconi, D. (1966). Mack Sennett. París: Seghers.

Uribe, M. (1983). La comedia del arte. Barcelona: Destino. 
